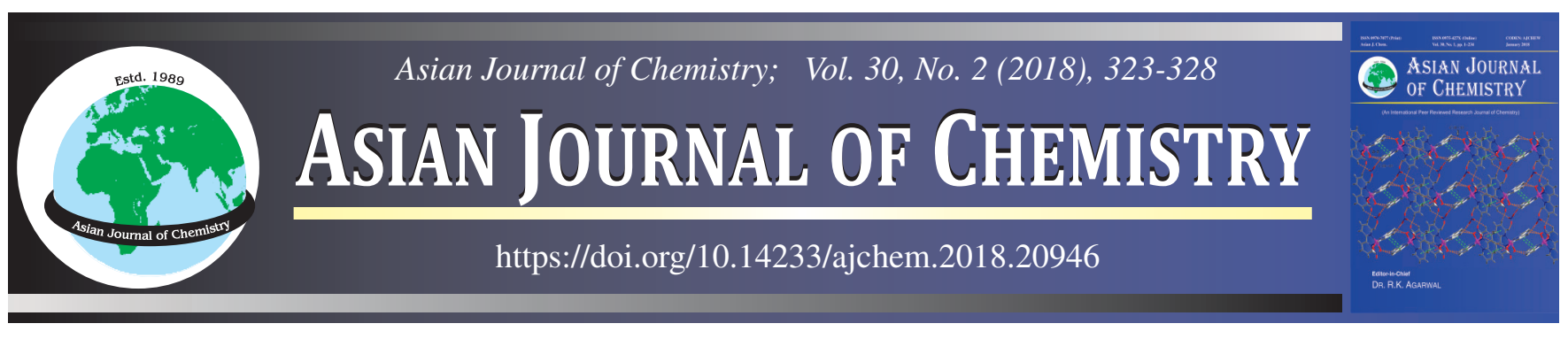

\title{
Ultrasonic Studies on Ion-Solvent Interactions of Tetra- $n$-butylammonium Bromide in Aqueous Solution of 1,3-Dioxolane and 2,2-Dimethoxypropane at Different Temperatures
}

\author{
Dayananda Sarangi ${ }^{1}$, Jagannath Panda $^{1}$, Rojalin Sahu ${ }^{1, *}$ and Braja B. Nanda ${ }^{2, *}$
}

${ }^{1}$ Department of Chemistry, KIIT University, Bhubaneswar-751 024, India

${ }^{2}$ Department of Chemistry, Vikram Deb Autonomous College, Jeypore-764 001, India

*Corresponding authors: E-mail: bbnanda.driems@gmail.com

Tetra- $n$-butylammonium bromide (TBAB) is made soluble in different solvents like $10 \%$ 1,3-dioxolane-water and $10 \%$ dimethoxypropanewater. Ultrasonic velocity $(\mathrm{U})$, density $(\rho)$ and coefficient of viscosity $(\eta)$ are determined at different temperatures i.e. at $298.15,303.15$, 308.15 and $313.15 \mathrm{~K}$. These values of ultrasonic velocity $(\mathrm{U})$, density $(\rho)$ and co-efficient of viscosity $(\eta)$ are used to calculate the thermo acoustic properties like isentropic compressibility $\left(\beta_{\mathrm{s}}\right)$, molar compressibility $(\mathrm{W})$, acoustic impedance $(\mathrm{Z})$, molar sound velocity $(\mathrm{R})$, relative association $\left(\mathrm{R}_{\mathrm{A}}\right)$, intermolecular free length $\left(\mathrm{L}_{\mathrm{f}}\right)$, free volume $\left(\mathrm{V}_{\mathrm{f}}\right)$, internal pressure $\left(\pi_{\mathrm{i}}\right)$, isothermal compressibility $\left(\beta_{\mathrm{T}}\right)$. The results obtained were analyzed to interpret the ion-ion and ion-solvent interactions occurring in the solutions.

Keywords: Tetra- $n$-butylammonium bromide, 1,3-Dioxolane, 2,2-Dimethoxy propane, Ion-solvent interaction, Ultrasonic.

\section{INTRODUCTION}

In recent years, the ultrasonic measurements have gained a lot of importance which is being intensively used in the field of agriculture, medical science engineering and industries. Such types of studies being used for the investigation of different chemical processes, play vital roles in the field of synthetic works [1]. The density and viscosity of tetra- $n$-butylammonium bromide is useful in elucidating the nature of ion-solvent interaction in aqueous and non-aqueous solutions [2]. Tetra alkylammonium salts are one of the important classes of organic compounds which are used as phase transfer catalyst [3]. As they contain both hydrophilic and hydrophobic groups their solution behaviour is very much attractive. Tetra$n$-butylammonium bromide is commonly used as a phase transfer catalyst which is used in various $\mathrm{C}-\mathrm{C}, \mathrm{C}-\mathrm{N}, \mathrm{C}-\mathrm{O}, \mathrm{C}-\mathrm{S}$ and $\mathrm{C}-\mathrm{P}$ bond forming reactions which are carried out by liquid-liquid and liquid-solid conditions [4]. Tetra- $n$-butylammonium bromide is used to synthesize different tetrabutylammonium salts through salt metathesis. When it is dissolved in aqueous solutions of 1,3-dioxolane (1,3-DO) and 2,2-dimethoxypropane (DMP), it affects the geometrical nature of water molecules. Thus a clathrate like structure is formed between water molecules and ammonium ions of tetra- $n$-butylammonium bromide [5]. These ions do not form any hydrogen bond but contain hydrophilic and hydrophobic groups. Aqueous solutions of tetra- $n$-butylammonium bromide show many properties like high viscosity with high temperature coefficients [6], high apparent molar heat capacities [7,8], low surface charge densities, high apparent molar volume [9] which are unusual. Tetraalkylammonium halides are large in size and are capable to arrange water particles around themselves subject to their alkyl group. 2,2-Dimethoxypropane is used for the dehydration of animal tissue because it scavenges water molecules more effectively in water-sensitive area and any trace quantity of water will react with 2,2-dimethoxypropane to form methanol and acetone. Similarly 1,3-dioxolane is a dominant aprotic solvent, used in formulations, in production methods or even as a reactant itself. Several applications of 1,3-dioxolane are due to its capability to quickly dissolve polar polymers, like epoxies, polyesters and urethanes etc. Due to its small size, it rapidly penetrates into the polymer, causing in fast application rates for several coating methods [10]. The present work aims at the measurement of ultrasonic velocity, density and viscosity of the solutions of tetra- $n$-butylammonium bromide in $10 \%(\mathrm{v} / \mathrm{v})$ aqueous 1,3-dioxolane and $10 \%$ (v/v) aqueous 2,2-dimethoxypropane at 298.15-313.15 K. Tetra alkylammonium salts are bigger in size and are known to adjust water molecules around them depending on their alkyl chain $[11,12]$. The aqueous solutions of tetra alkylammonium bromide show high viscosities and large temperature coefficients [13]. The ion-solvent and ion-ion interactions for tetra alkylammonium salts have been 
reported from density and viscosity measurements by Nikam et al. $[14,15]$. Thermo-acoustic properties of tetra- $n$-butylammonium bromide in aqueous solution has recently been done $[16,17]$. There is mild studies about these properties of tetra- $n$-butylammonium bromide in mixed solvents like 1,3dioxolane and 2,2-dimethoxypropane.

\section{EXPERIMENTAL}

The chemicals used are tetra- $n$-butylammonium bromide, 1,3-dioxlane and 2,2-dimethoxy propane. These are of Sigma Aldrich, German variety with $99 \%$ purity. $10 \%$ solutions of 1,3-dioxolane and 2,2-dimethoxypropane in water were prepared which were used as solvents. Tetra- $n$-butylammonium bromide was purified by recrystallization from acetone and the recrystallized salt was dried at $333.15 \mathrm{~K}$ for $48 \mathrm{~h}$. The sample description is presented in Table- 1 .

The tetra- $n$-butylammonium bromide solutions in $10 \%$ aqueous solutions of each of 1,3-dioxolane and 2,2-dimethoxypropane were prepared by mass in molar basis. Electronic balance of model ABJ-220-4NM (KERN, Germany) was used to record the masses of solute and solvents with a precision of $\pm 0.01 \mathrm{mg}$. The density ( $\rho$ ) of mixture solutions were measured with Rudolph DDM 2911 laboratory density meter. It was calibrated with the samples provided by the manufacturer to confirm the accuracy of the measurement. The uncertainty in density measurements was determined to be $0.00125 \mathrm{~g} \mathrm{~cm}^{-3}$. The molarity of solutions was converted to molality using standard expressions [18-21] and density values. The ultrasonic velocity of solutions were measured with ultrasonic interferometer, model-M-84 (Mittal Enterprises, India,) with a frequency of $2 \mathrm{MHz}$. Uncertainty in ultrasonic velocity measurements were precise to $\pm 0.1 \mathrm{~m} \mathrm{~s}^{-1}$. The instrument was calibrated with triply distilled water. The temperature of the test liquids was maintained at 298.15-313.15 $\mathrm{K}$ to an accuracy of $\pm 0.01 \mathrm{~K}$ [22].

\section{Theory}

The velocity of sound is affected by parameters like temperature, frequency, density and concentration of solution. This paper reports the various parameters from the experimentally measured values viz., isentropic compressibility $\left(\beta_{\mathrm{S}}\right)=1 / \mathrm{U}^{2} \rho$; isothermal compressibility $\left(\beta_{\mathrm{T}}\right)=17.1 \times 10^{-4} /\left(\mathrm{T}^{4 / 9} \rho^{4 / 3} \mathrm{U}^{2}\right)$; molar compressibility $(\mathrm{W})=\mathrm{M}_{\text {eff }} \times \rho^{-1} \times \beta_{\mathrm{s}}^{-1 / 7}$; acoustic impendance $(Z)=U \times \rho$; molar sound velocity $(R)=M_{\text {eff }} \times \rho$; relative association $\left(R_{A}\right)=\left(\rho / \rho_{0}\right) \times\left(U_{0 /} U\right)^{1 / 3}$; intermolecular free length $\left(\mathrm{L}_{\mathrm{f}}\right)=\mathrm{K}_{\mathrm{T}} \beta_{\mathrm{s}}^{1 / 2 ;}$ where $\mathrm{K}_{\mathrm{T}}$ is the Jacobson's constant [23] and is equal to $(93.875+0.375 \mathrm{~T}) \times 10^{-8}$ and is equal to $207.5 \times 10^{-8}$ at $303.15 \mathrm{~K}$. Free volume $\left(\mathrm{V}_{\mathrm{f}}\right)=\left[\left(\mathrm{M}_{\mathrm{eff} \times} \mathrm{U}\right) /(\mathrm{K} \times\right.$ $\eta)]^{3 / 2}$; where $\mathrm{K}=4.28 \times 10^{9}$ for all types of liquids and $\mathrm{M}_{\mathrm{eff}}$ is called effective molecular mass i.e. $\mathrm{M}_{\mathrm{eff}}=\Sigma \mathrm{m}_{\mathrm{i}} \mathrm{x}_{\mathrm{i}}$, where $\mathrm{m}_{\mathrm{i}}$ and $\mathrm{x}_{\mathrm{i}}$ represent the molar mass and the mole fraction of the components respectively. Internal pressure $\left(\pi_{\mathrm{i}}\right)=\mathrm{b}^{\prime} \mathrm{R} \times \mathrm{T}(\mathrm{K} \eta /$ $\mathrm{U})^{1 / 2}\left(\rho^{2 / 3} / \mathrm{M}_{\mathrm{eff}}{ }^{7 / 6}\right)$.

\section{RESULTS AND DISCUSSION}

Density, speed of sound and compressibility: The ultrasonic velocity, density and viscosity of tetra- $n$-butylammonium bromide in aqueous solution of 1,3-dioxolane and 2,2-dimethoxypropane at 298.15-313.15 K are given in Table-2. The analysis of the data from the table, reveals that with increase in concentration of tetra- $n$-butylammonium bromide, the value of density ( $\rho)$ increases. As the concentration increases number of particles in a particular area increases which results in contraction of volume of solution, thereby increase of density. Due to this, there is quick transfer of sound velocity in the solution. Hence ultrasonic velocity increases with the increase in concentration of tetra- $n$-butylammonium bromide (Fig. 1). This indicates that there is a strong interaction between the molecules of tetra$n$-butyl-ammonium bromide in solution. The values of isentropic compressibility $\left(\beta_{\mathrm{s}}\right)$, isothermal compressibility $\left(\beta_{\mathrm{T}}\right)$ and molar compressibility (W) were determined (Table-3). The decrease of $\beta_{\mathrm{s}}$ values with increase in tetra- $n$-butylammonium bromide concentration is due to the influence of the interaction of ammonium ions with 1,3-dioxolane and 2,2-dimethoxypropane, so called electrostriction. In these solutions, the solute dissociated in to oppositely charged ions due to ion solvent interactions and there will be a sphere of positive and negative charged ions around a charged ion in solution [24]. Tetra $n$ butylammonium bromide ions associate themselves with water molecules as well as the complex of 1,3-dioxolane-water or 2,2-dimethoxy propane-water mixture, resulting in the decrease in compressibility and hence increase in ultrasonic velocity. The decrease in compressibility is expected due to the structure-making ability of tetra- $n$-butylammonium bromide [25]. As the solvent molecules are oriented in presence of electrostatic forces of ions, the solvent particles are more rigidly packed in case of primary solvation of solvent in comparison to the packing which occurs in absence of ions. Due to this fact the solvent-molecules are compressed when ions are introduced into them. This compression of medium caused by electrostatic force of ions is called as electrostriction. Solvent particles do not respond to any further use of pressure as these are compacted. As a result the isentropic compressibility $\left(\beta_{\mathrm{s}}\right)$ as well as isothermal compressibility $\left(\beta_{\mathrm{T}}\right)$ decreases due to which the solution becomes harder to compress. So the two factors which are used to describe the arrangement of molecules in liquid medium are isentropic compressibility and internal pressure. The value of molar compressibility increases with increase in temperature. This may be due to the decrease in bulkiness of tetra- $n$-butylammonium bromide which is due to the reason that organic co-solvents filled the interstitial spaces of water.

TABLE-1 SAMPLE DESCRIPTION

\begin{tabular}{lcccc}
\hline \multicolumn{1}{c}{ Chemical name } & Source & Initial mass fraction purity & Purification method & Final mass fraction purity \\
\hline Tetra- $n$-butylammonium bromide & Sigma & 0.99 & Used as procured & 0.99 \\
1,3-Dioxolane & Sigma & 0.99 & Purified by standard methods & 0.99 \\
2,2-Dimethoxy propane & Sigma & 0.99 & Purified by standard methods & 0.99 \\
\hline
\end{tabular}


DENSITY ( $\rho$ ), ULTRASONIC VELOCITY (U) AND VISCOSITY ( $\eta$ ) OF TETRA- $n$-BUTYLAMMONIUM BROMIDE IN $10 \%$ 1,3-DIOXOLANE + WATER AND $10 \%$ 2,2-DIMETHOXYPROPANE + WATER SOLUTIONS AT DIFFERENT TEMPERATURES AND ATMOSPHERIC PRESSURE

\begin{tabular}{|c|c|c|c|c|c|c|c|c|c|c|c|c|}
\hline \multirow{2}{*}{$\begin{array}{l}\text { Conc. } \\
(\mathrm{mol} \\
\left.\mathrm{kg}^{-1}\right)\end{array}$} & \multicolumn{3}{|c|}{$298.15 \mathrm{~K}$} & \multicolumn{3}{|c|}{$303.15 \mathrm{~K}$} & \multicolumn{3}{|c|}{$308.15 \mathrm{~K}$} & \multicolumn{3}{|c|}{$313.15 \mathrm{~K}$} \\
\hline & $\begin{array}{c}\rho \\
\left(\mathrm{kg} \mathrm{m}^{-3}\right)\end{array}$ & $\begin{array}{c}\mathrm{U} \\
\left(\mathrm{m} \mathrm{s}^{-1}\right)\end{array}$ & $\begin{array}{c}\eta \\
\left(\mathrm{NS} \mathrm{m}^{-3}\right)\end{array}$ & $\begin{array}{c}\rho \\
\left(\mathrm{kg} \mathrm{m}^{-3}\right) \\
\end{array}$ & $\begin{array}{c}\mathrm{U} \\
\left(\mathrm{m} \mathrm{s}^{-1}\right)\end{array}$ & $\begin{array}{c}\eta \\
\left(\mathrm{NS} \mathrm{m} \mathrm{m}^{-3}\right) \\
\end{array}$ & $\begin{array}{c}\rho \\
\left(\mathrm{kg} \mathrm{m}^{-3}\right) \\
\end{array}$ & $\begin{array}{c}\mathrm{U} \\
\left(\mathrm{m} \mathrm{s}^{-1}\right)\end{array}$ & $\begin{array}{c}\eta \\
\left(\mathrm{NS} \mathrm{m}^{-3}\right) \\
\end{array}$ & $\begin{array}{c}\rho \\
\left(\mathrm{kg} \mathrm{m}^{-3}\right)\end{array}$ & $\begin{array}{c}\mathrm{U} \\
\left(\mathrm{m} \mathrm{s}^{-1}\right)\end{array}$ & $\begin{array}{c}\eta \\
\left(\mathrm{NS} \mathrm{m}^{-3}\right) \\
\end{array}$ \\
\hline \multicolumn{13}{|c|}{ Tetra- $n$-butylammonium bromide in $10 \%$ 1,3-dioxolane + water } \\
\hline 0.000 & 1009.0 & 1553.5 & 0.9362 & 1008.1 & 1558.0 & 0.8356 & 1006.7 & 1564.0 & 0.7495 & 1005.2 & 1568.8 & 0.6750 \\
\hline 0.001 & 1009.0 & 1554.7 & 0.9374 & 1008.1 & 1559.0 & 0.8366 & 1006.7 & 1565.2 & 0.7504 & 1005.2 & 1569.6 & 0.6759 \\
\hline 0.005 & 1009.0 & 1558.0 & 0.9462 & 1008.1 & 1562.2 & 0.8430 & 1006.7 & 1568.4 & 0.7563 & 1005.2 & 1572.8 & 0.6812 \\
\hline 0.008 & 1009.1 & 1558.8 & 0.9480 & 1008.2 & 1563.0 & 0.8457 & 1006.8 & 1568.9 & 0.7588 & 1005.2 & 1573.4 & 0.6835 \\
\hline 0.010 & 1009.2 & 1559.2 & 0.9492 & 1008.2 & 1563.3 & 0.8476 & 1006.8 & 1569.4 & 0.7606 & 1005.2 & 1574.8 & 0.6852 \\
\hline 0.021 & 1009.3 & 1562.1 & 0.9524 & 1008.4 & 1566.2 & 0.8511 & 1006.8 & 1572.0 & 0.7637 & 1005.3 & 1578.3 & 0.6880 \\
\hline 0.042 & 1009.8 & 1564.5 & 0.9580 & 1008.7 & 1568.2 & 0.8557 & 1007.0 & 1573.6 & 0.7680 & 1005.4 & 1580.0 & 0.6918 \\
\hline 0.064 & 1010.2 & 1567.0 & 0.9655 & 1009.0 & 1570.8 & 0.8613 & 1007.2 & 1577.0 & 0.7737 & 1005.6 & 1583.8 & 0.6970 \\
\hline 0.087 & 1010.6 & 1570.2 & 0.9685 & 1009.3 & 1574.2 & 0.8636 & 1007.4 & 1580.5 & 0.7763 & 1005.8 & 1587.0 & 0.6994 \\
\hline 0.110 & 1011.1 & 1573.0 & 0.9752 & 1009.7 & 1576.8 & 0.8694 & 1008.0 & 1582.4 & 0.7803 & 1006.0 & 1589.0 & 0.7030 \\
\hline 0.133 & 1011.6 & 1577.2 & 0.9749 & 1010.1 & 1580.9 & 0.8690 & 1008.5 & 1586.0 & 0.7798 & 1006.3 & 1592.0 & 0.7024 \\
\hline \multicolumn{13}{|c|}{ Tetra- $n$-butylammonium bromide in $10 \%$ 2,2-dimethoxypropane + water } \\
\hline 0.000 & 981.45 & 1500.0 & 0.9448 & 979.81 & 1505.5 & 0.8384 & 976.53 & 1514.0 & 0.7483 & 974.64 & 1521.7 & 0.6707 \\
\hline 0.001 & 981.46 & 1501.0 & 0.9482 & 979.81 & 1506.5 & 0.8422 & 976.54 & 1514.8 & 0.7518 & 974.65 & 1522.5 & 0.6742 \\
\hline 0.005 & 981.53 & 1504.8 & 0.9546 & 979.87 & 1509.5 & 0.8473 & 976.58 & 1517.5 & 0.7564 & 974.68 & 1524.9 & 0.6781 \\
\hline 0.008 & 981.58 & 1506.5 & 0.9564 & 979.92 & 1511.0 & 0.8496 & 976.62 & 1518.6 & 0.7585 & 974.72 & 1525.7 & 0.6794 \\
\hline 0.011 & 981.64 & 1507.4 & 0.9581 & 979.97 & 1512.0 & 0.8504 & 976.67 & 1519.0 & 0.7592 & 974.75 & 1526.5 & 0.6807 \\
\hline 0.021 & 981.91 & 1509.5 & 0.9617 & 980.19 & 1514.3 & 0.8536 & 976.85 & 1521.0 & 0.7622 & 974.90 & 1528.7 & 0.6834 \\
\hline 0.044 & 982.45 & 1511.0 & 0.9676 & 980.61 & 1516.0 & 0.8589 & 977.25 & 1523.5 & 0.7670 & 975.20 & 1531.2 & 0.6877 \\
\hline 0.066 & 983.01 & 1513.0 & 0.9751 & 981.02 & 1518.0 & 0.8656 & 977.65 & 1526.0 & 0.7730 & 975.50 & 1533.9 & 0.6931 \\
\hline 0.090 & 983.62 & 1515.5 & 0.9842 & 981.52 & 1521.3 & 0.8736 & 978.05 & 1529.3 & 0.7804 & 975.80 & 1537.2 & 0.6998 \\
\hline 0.113 & 984.34 & 1517.5 & 0.9949 & 982.08 & 1523.0 & 0.8832 & 978.50 & 1530.6 & 0.7891 & 976.20 & 1538.6 & 0.7077 \\
\hline 0.137 & 984.91 & 1519.1 & 1.0016 & 982.64 & 1525.5 & 0.8891 & 978.95 & 1533.5 & 0.7945 & 976.60 & 1541.6 & 0.7126 \\
\hline
\end{tabular}

Uncertainty in the density values $\pm 0.00125 \mathrm{~g} \mathrm{~cm}^{-3}$; Uncertainties in the molality is $\pm 0.0002\left(\mathrm{~mol} \mathrm{~kg}^{-1}\right)$

TABLE-3

ISENTROPIC COMPRESSIBILITY $\left(\beta_{\mathrm{S}}\right)$, MOLAR COMPRESSIBILITY (W), ISOTHERMAL COMPRESSIBILITY $\left(\beta_{\mathrm{T}}\right)$ OF TETRA- $n$-BUTYLAMMONIUM BROMIDE IN $10 \%$ 1,3-DIOXOLANE + WATER AND $10 \%$ 2,2-DIMETHOXYPROPANE + WATER SOLUTIONS AT DIFFERENT TEMPERATURES AND ATMOSPHERIC PRESSURE

\begin{tabular}{|c|c|c|c|c|c|c|c|c|c|c|c|c|}
\hline \multirow{2}{*}{$\begin{array}{c}\text { Conc. } \\
(\mathrm{mol} \\
\mathrm{kg}^{-1} \text { ) }\end{array}$} & \multicolumn{3}{|c|}{$298.15 \mathrm{~K}$} & \multicolumn{3}{|c|}{$303.15 \mathrm{~K}$} & \multicolumn{3}{|c|}{$308.15 \mathrm{~K}$} & \multicolumn{3}{|c|}{$313.15 \mathrm{~K}$} \\
\hline & $\begin{array}{l}\beta_{\mathrm{s}} \times 10^{10} \\
\left(\mathrm{~m}^{2} \mathrm{~N}^{-1}\right)\end{array}$ & $\begin{array}{c}\mathrm{W} \times 10^{4} \\
\left(\mathrm{~N}^{-1} \mathrm{~m}^{-1}\right)\end{array}$ & $\begin{array}{l}\beta_{\mathrm{T}} \times 10^{15} \\
\left(\mathrm{~m}^{2} \mathrm{~N}^{-1}\right)\end{array}$ & $\begin{array}{l}\beta_{\mathrm{s}} \times 10^{10} \\
\left(\mathrm{~m}^{2} \mathrm{~N}^{-1}\right)\end{array}$ & $\begin{array}{c}\mathrm{W} \times 10^{4} \\
\left(\mathrm{~N}^{-1} \mathrm{~m}^{-1}\right)\end{array}$ & $\begin{array}{l}\beta_{\mathrm{T}} \times 10^{15} \\
\left(\mathrm{~m}^{2} \mathrm{~N}^{-1}\right)\end{array}$ & $\begin{array}{l}\beta_{\mathrm{s}} \times 10^{10} \\
\left(\mathrm{~m}^{2} \mathrm{~N}^{-1}\right)\end{array}$ & $\begin{array}{c}\mathrm{W} \times 10^{4} \\
\left(\mathrm{~N}^{-1} \mathrm{~m}^{-1}\right)\end{array}$ & $\begin{array}{l}\beta_{\mathrm{T}} \times 10^{15} \\
\left(\mathrm{~m}^{2} \mathrm{~N}^{-1}\right)\end{array}$ & $\begin{array}{l}\beta_{\mathrm{s}} \times 10^{10} \\
\left(\mathrm{~m}^{2} \mathrm{~N}^{-1}\right)\end{array}$ & $\begin{array}{c}\mathrm{W} \times 10^{4} \\
\left(\mathrm{~N}^{-1} \mathrm{~m}^{-1}\right)\end{array}$ & $\begin{array}{l}\beta_{\mathrm{T}} \times 10^{15} \\
\left(\mathrm{~m}^{2} \mathrm{~N}^{-1}\right)\end{array}$ \\
\hline \multicolumn{13}{|c|}{ Tetra- $n$-butylammonium bromide in $10 \% 1,3$-dioxolane + water } \\
\hline 0.0000 & 4.107 & 4.253 & 5.565 & 4.092 & 4.259 & 5.498 & 4.071 & 4.269 & 5.427 & 4.058 & 4.278 & 5.366 \\
\hline 0.0010 & 4.101 & 4.266 & 5.556 & 4.087 & 4.273 & 5.491 & 4.065 & 4.283 & 5.418 & 4.054 & 4.292 & 5.360 \\
\hline 0.0051 & 4.083 & 4.321 & 5.532 & 4.070 & 4.328 & 5.469 & 4.048 & 4.338 & 5.396 & 4.037 & 4.347 & 5.339 \\
\hline 0.0076 & 4.078 & 4.355 & 5.526 & 4.065 & 4.361 & 5.463 & 4.046 & 4.371 & 5.393 & 4.034 & 4.381 & 5.334 \\
\hline 0.0102 & 4.076 & 4.388 & 5.523 & 4.064 & 4.395 & 5.460 & 4.043 & 4.405 & 5.389 & 4.032 & 4.415 & 5.325 \\
\hline 0.0207 & 4.060 & 4.524 & 5.501 & 4.048 & 4.532 & 5.439 & 4.029 & 4.542 & 5.371 & 4.019 & 4.553 & 5.301 \\
\hline 0.0423 & 4.046 & 4.799 & 5.481 & 4.037 & 4.807 & 5.423 & 4.021 & 4.819 & 5.359 & 4.009 & 4.831 & 5.288 \\
\hline 0.0644 & 4.031 & 5.079 & 5.461 & 4.022 & 5.088 & 5.403 & 4.003 & 5.101 & 5.334 & 3.990 & 5.114 & 5.262 \\
\hline 0.0870 & 4.013 & 5.362 & 5.435 & 4.000 & 5.372 & 5.377 & 3.984 & 5.387 & 5.309 & 3.973 & 5.401 & 5.240 \\
\hline 0.1099 & 3.997 & 5.648 & 5.412 & 3.983 & 5.659 & 5.357 & 3.965 & 5.673 & 5.292 & 3.952 & 5.689 & 5.224 \\
\hline 0.1332 & 3.974 & 5.937 & 5.380 & 3.961 & 5.949 & 5.326 & 3.945 & 5.962 & 5.265 & 3.936 & 5.980 & 5.203 \\
\hline 0.000 & 4.528 & 4.265 & 6.193 & 4.506 & 4.276 & 6.116 & 4.491 & 4.295 & 6.031 & 4.478 & 4.308 & 5.943 \\
\hline 0.001 & 4.522 & 4.279 & 6.184 & 4.500 & 4.290 & 6.108 & 4.486 & 4.309 & 6.024 & 4.473 & 4.322 & 5.936 \\
\hline 0.005 & 4.499 & 4.336 & 6.153 & 4.482 & 4.346 & 6.083 & 4.470 & 4.365 & 6.003 & 4.459 & 4.379 & 5.918 \\
\hline 0.008 & 4.489 & 4.371 & 6.139 & 4.473 & 4.382 & 6.071 & 4.464 & 4.401 & 5.994 & 4.454 & 4.414 & 5.911 \\
\hline 0.011 & 4.483 & 4.406 & 6.131 & 4.469 & 4.417 & 6.062 & 4.461 & 4.435 & 5.990 & 4.449 & 4.449 & 5.905 \\
\hline 0.021 & 4.470 & 4.546 & 6.112 & 4.455 & 4.557 & 6.042 & 4.448 & 4.576 & 5.973 & 4.436 & 4.591 & 5.886 \\
\hline 0.044 & 4.458 & 4.829 & 6.095 & 4.440 & 4.842 & 6.025 & 4.432 & 4.863 & 5.950 & 4.420 & 4.878 & 5.865 \\
\hline 0.066 & 4.444 & 5.117 & 6.074 & 4.427 & 5.131 & 6.006 & 4.416 & 5.154 & 5.927 & 4.403 & 5.171 & 5.842 \\
\hline 0.090 & 4.426 & 5.409 & 6.049 & 4.405 & 5.425 & 5.976 & 4.395 & 5.449 & 5.899 & 4.382 & 5.468 & 5.814 \\
\hline 0.113 & 4.412 & 5.702 & 6.027 & 4.389 & 5.719 & 5.958 & 4.378 & 5.745 & 5.885 & 4.365 & 5.765 & 5.801 \\
\hline 0.137 & 4.400 & 5.997 & 6.010 & 4.376 & 6.017 & 5.934 & 4.367 & 6.045 & 5.859 & 4.351 & 6.067 & 5.775 \\
\hline
\end{tabular}



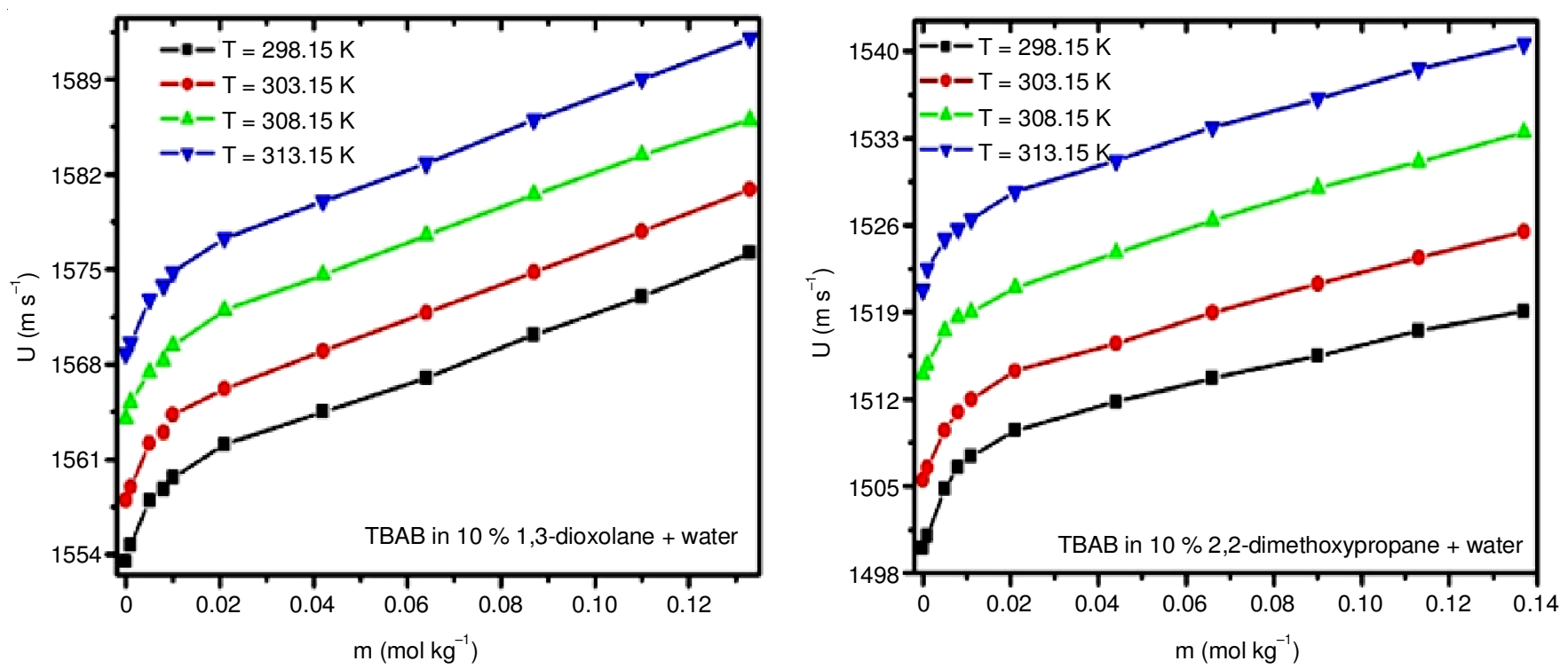

Fig. 1. Plot of ultrasonic velocity (U) vs. molality (m) of solutions of tetra- $n$-butylammonium bromide in (a) $10 \%$ 1,3-dioxolane + water and (b) in $10 \%$ 2,2-dimethoxypropane + water at 298.15-313.15 K

Acoustic impedance, molar sound velocity and relative association: Thermo acoustic parameters were calculated from their formulae. The values of acoustic impedance $(\mathrm{Z})$, molar sound velocity $(\mathrm{R})$ and relative association $\left(\mathrm{R}_{\mathrm{A}}\right)$ of tetra- $n$ butylammonium bromide in aqueous solution of 1,3-dioxolane and 2,2-dimethoxypropane at 298.15-313.15 $\mathrm{K}$ has been obtained (Table-4). From the data, it is analyzed that the value of acoustic impedance $(\mathrm{Z})$ increase in all solutions with increase in concentration of tetra- $n$-butylammonium bromide [26]. The acoustic impedance explains the elastic property of the medium whose value is influenced by the geometric distortion of the solution. The elastic property of the solution increases with increase in concentration of tetra- $n$-butylammonium bromide in 1,3-dioxolane and 2,2-dimethoxypropane. It has been observed that with increase in concentration of tetra- $n$-butylammonium bromide in solvents like 1,3-dioxolane and 2,2-dimethoxy-

TABLE-4

MOLAR COMPRESSIBILITY (W), MOLAR SOUND VELOCITY (R) AND RELATIVE ASSOCIATION $\left(\mathrm{R}_{\mathrm{A}}\right)$ OF TETRA- $n$-BUTYLAMMONIUM BROMIDE IN $10 \%$ 1,3-DIOXOLANE + WATER AND $10 \%$ 2,2-DIMETHOXYPROPANE + WATER SOLUTIONS AT DIFFERENT TEMPERATURES

\begin{tabular}{|c|c|c|c|c|c|c|c|c|c|c|c|c|}
\hline \multirow[b]{2}{*}{$\begin{array}{l}\text { Conc. } \\
(\mathrm{mol} \\
\left.\mathrm{kg}^{-1}\right)\end{array}$} & \multicolumn{3}{|c|}{$298.15 \mathrm{~K}$} & \multicolumn{3}{|c|}{$303.15 \mathrm{~K}$} & \multicolumn{3}{|c|}{$308.15 \mathrm{~K}$} & \multicolumn{3}{|c|}{$313.15 \mathrm{~K}$} \\
\hline & $\begin{array}{c}\mathrm{Z} \times 10^{-6} \\
(\mathrm{Kg} \\
\left.\mathrm{m}^{-2} \mathrm{~s}^{-1}\right)\end{array}$ & $\mathrm{R}_{\mathrm{A}}$ & $\begin{array}{c}\mathrm{R} \times 10^{4} \\
\left(\mathrm{~m}^{-8 / 3}\right. \\
\left.\mathrm{s}^{-1 / 3}\right)\end{array}$ & $\begin{array}{c}\mathrm{Z} \times 10^{-6} \\
(\mathrm{Kg} \\
\left.\mathrm{m}^{-2} \mathrm{~s}^{-1}\right)\end{array}$ & $\mathrm{R}_{\mathrm{A}}$ & $\begin{array}{c}\mathrm{R} \times 10^{4} \\
\left(\mathrm{~m}^{-8 / 3}\right. \\
\left.\mathrm{s}^{-1 / 3}\right)\end{array}$ & $\begin{array}{c}\mathrm{Z} \times 10^{-6} \\
(\mathrm{Kg} \\
\left.\mathrm{m}^{-2} \mathrm{~s}^{-1}\right)\end{array}$ & $\mathrm{R}_{\mathrm{A}}$ & $\begin{array}{c}\mathrm{R} \times 10^{4} \\
\left(\mathrm{~m}^{-8 / 3}\right. \\
\left.\mathrm{s}^{-1 / 3}\right)\end{array}$ & $\begin{array}{c}\mathrm{Z} \times 10^{-6} \\
(\mathrm{Kg} \\
\left.\mathrm{m}^{-2} \mathrm{~s}^{-1}\right)\end{array}$ & $\mathrm{R}_{\mathrm{A}}$ & $\begin{array}{c}\mathrm{R} \times 10^{4} \\
\left(\mathrm{~m}^{-8 / 3}\right. \\
\left.\mathrm{s}^{-1 / 3}\right)\end{array}$ \\
\hline \multicolumn{13}{|c|}{ Tetra- $n$-butylammonium bromide in $10 \% 1,3$-dioxolane + water } \\
\hline 0.0000 & 1.567 & 1.000 & 2.246 & 1.571 & 1.000 & 2.251 & 1.574 & 1.000 & 2.257 & 1.577 & 0.999 & 2.262 \\
\hline 0.0010 & 1.569 & 1.000 & 2.254 & 1.572 & 0.999 & 2.258 & 1.576 & 0.999 & 2.264 & 1.578 & 0.999 & 2.269 \\
\hline 0.0051 & 1.572 & 0.999 & 2.283 & 1.575 & 0.998 & 2.287 & 1.579 & 0.998 & 2.293 & 1.581 & 0.999 & 2.299 \\
\hline 0.0076 & 1.573 & 0.999 & 2.301 & 1.576 & 0.998 & 2.305 & 1.579 & 0.998 & 2.311 & 1.582 & 0.998 & 2.317 \\
\hline 0.0102 & 1.573 & 0.999 & 2.318 & 1.576 & 0.998 & 2.323 & 1.580 & 0.998 & 2.329 & 1.583 & 0.998 & 2.335 \\
\hline 0.0207 & 1.577 & 0.999 & 2.390 & 1.579 & 0.998 & 2.395 & 1.583 & 0.998 & 2.401 & 1.585 & 0.997 & 2.408 \\
\hline 0.0423 & 1.580 & 0.998 & 2.536 & 1.582 & 0.998 & 2.541 & 1.585 & 0.998 & 2.548 & 1.589 & 0.997 & 2.555 \\
\hline 0.0644 & 1.583 & 0.998 & 2.684 & 1.585 & 0.998 & 2.689 & 1.588 & 0.997 & 2.697 & 1.593 & 0.997 & 2.705 \\
\hline 0.0870 & 1.587 & 0.998 & 2.833 & 1.589 & 0.998 & 2.840 & 1.592 & 0.997 & 2.849 & 1.596 & 0.996 & 2.857 \\
\hline 0.1099 & 1.591 & 0.998 & 2.984 & 1.592 & 0.998 & 2.991 & 1.595 & 0.997 & 3.000 & 1.600 & 0.996 & 3.010 \\
\hline 0.1332 & 1.596 & 0.998 & 3.137 & 1.597 & 0.998 & 3.145 & 1.600 & 0.997 & 3.153 & 1.604 & 0.996 & 3.164 \\
\hline 0.000 & 1.472 & 1.000 & 2.258 & 1.475 & 1.000 & 2.265 & 1.478 & 0.999 & 2.277 & 1.483 & 0.998 & 2.285 \\
\hline 0.001 & 1.473 & 1.000 & 2.266 & 1.476 & 1.000 & 2.272 & 1.479 & 0.999 & 2.284 & 1.484 & 0.998 & 2.292 \\
\hline 0.005 & 1.477 & 0.999 & 2.296 & 1.479 & 0.999 & 2.302 & 1.482 & 0.998 & 2.314 & 1.486 & 0.998 & 2.322 \\
\hline 0.008 & 1.479 & 0.999 & 2.315 & 1.481 & 0.999 & 2.321 & 1.483 & 0.998 & 2.333 & 1.487 & 0.997 & 2.341 \\
\hline 0.011 & 1.480 & 0.999 & 2.333 & 1.482 & 0.999 & 2.340 & 1.484 & 0.998 & 2.351 & 1.488 & 0.997 & 2.360 \\
\hline 0.021 & 1.482 & 0.998 & 2.408 & 1.484 & 0.998 & 2.414 & 1.486 & 0.998 & 2.426 & 1.490 & 0.997 & 2.435 \\
\hline 0.044 & 1.484 & 0.999 & 2.557 & 1.487 & 0.998 & 2.565 & 1.489 & 0.998 & 2.578 & 1.493 & 0.997 & 2.588 \\
\hline 0.066 & 1.487 & 0.999 & 2.710 & 1.489 & 0.998 & 2.718 & 1.492 & 0.998 & 2.732 & 1.496 & 0.996 & 2.743 \\
\hline 0.090 & 1.491 & 0.999 & 2.864 & 1.493 & 0.998 & 2.874 & 1.496 & 0.997 & 2.889 & 1.500 & 0.996 & 2.901 \\
\hline 0.113 & 1.494 & 0.999 & 3.019 & 1.496 & 0.998 & 3.030 & 1.499 & 0.998 & 3.046 & 1.503 & 0.996 & 3.059 \\
\hline 0.137 & 1.496 & 0.999 & 3.176 & 1.499 & 0.998 & 3.188 & 1.502 & 0.997 & 3.205 & 1.506 & 0.996 & 3.218 \\
\hline
\end{tabular}


propane, the molar sound velocity $(\mathrm{R})$ increases [27]. Relative association $\left(R_{\mathrm{A}}\right)$ [28] is used to study the ion-ion and ionsolvent interactions. The factors which affect the relative association are association of solution with solute particles that leads to increase in association and breaking of the associated solvent molecules on addition of solute tetra- $n$-butylammonium bromide that leads to decrease in relative association. During this study it is observed that the relative association $\left(\mathrm{R}_{\mathrm{A}}\right)$ decreases with increase in concentration of tetra- $n$-butylammonium bromide. This indicates that by adding solute, the association of solvent molecules with solute decreases.

Free length, free volume and internal pressure: The values of free length $\left(\mathrm{L}_{\mathrm{f}}\right)$, free volume $\left(\mathrm{V}_{\mathrm{f}}\right)$ and internal pressure $\left(\pi_{\mathrm{i}}\right)$ of tetra- $n$-butylammonium bromide in aqueous solution of 1,3-dioxolane and 2,2-dimethoxypropane at 298.15-313.15 $\mathrm{K}$ were calculated (Table-5). The free volume $\left(\mathrm{V}_{\mathrm{f}}\right)$ is nothing but the available volume around centre of the molecule in a liquid. To determine the structure of liquid, the strong repulsion which exists inside the liquid with relatively low cohesive forces providing the internal pressure responsible for attracting the liquid molecules together is known. It is found that the internal pressure $\left(\pi_{\mathrm{i}}\right)$ is sensitive towards attractive forces and the free volume towards repulsive forces [29]. The free volume increases regularly with increase in the concentration of tetra$n$-butylammonium bromide in 1,3-dioxolane and 2,2-dimethoxypropane. But it is observed that $\pi_{\mathrm{i}}$ decreases with increase in concentration of tetra- $n$-butylammonium bromide and decreases with increase in temperature. The increase in $V_{f}$ (Fig. 2) and decrease of $\pi_{\mathrm{i}}$ indicates the formation of less hard solvation layer around the ammonium ion of tetra- $n$-butylammonium bromide which lead to decrease in free length $\left(\mathrm{L}_{\mathrm{f}}\right)$. On the other hand it is known from the model proposed by Eyring and Kincaid [28] that sound speed will increase with decrease in intermolecular free length. This is found in the solutions of tetra- $n$-butylammonium bromide in 1,3-dioxolane and 2,2dimethoxypropane. The ratio between free volumes to molar volume is a sign of crowdedness of the ions in solution. The frictional force formed due to various layers of liquid, increases with increase in ions and non-polar solvent content in solution. Due to this effect the ultrasonic absorption increases [30]. Suryanarayana et al. [31] expressed that the cohesive force and free energy of activation $(\Delta \mathrm{G})$ are almost equal to each other.

\section{Conclusion}

In this present work, the experimentally measured values of density, ultrasonic velocity and co-efficient of viscosity at temperatures from 298.15-315.15 K for mixtures of tetra- $n$ butylammonium bromide in 1,3-dioxolane and 2,2-dimethoxypropane were used to calculate the thermodynamic and thermo acoustic properties and the results obtained were analyzed to interpret the ion-ion and ion-solvent interactions occurring in the solutions. It has been observed that the values of density and ultrasonic velocity increase with increase in concentration of tetra- $n$-butylammonium bromide in solution. Except the ultrasonic velocity which increases with temperature, other two parameters such as density and viscosity decrease with temperature. This implies that the increase in ion solvent inter-

TABLE-5

INTERNAL PRESSURE $\left(\pi_{\mathrm{I}}\right)$, FREE LENGTH $\left(\mathrm{L}_{\mathrm{F}}\right)$ AND FREE VOLUME $\left(\mathrm{V}_{\mathrm{F}}\right)$ OF TETRA- $n$-BUTYLAMMONIUM BROMIDE IN $10 \%$ 1,3-DIOXOLANE + WATER AND $10 \%$ 2, 2-DIMETHOXYPROPANE + WATER SOLUTIONS AT DIFFERENT TEMPERATURES AND ATMOSPHERIC PRESSURE

\begin{tabular}{|c|c|c|c|c|c|c|c|c|c|c|c|c|}
\hline \multirow[b]{2}{*}{$\begin{array}{l}\text { Conc. } \\
(\mathrm{mol} \\
\left.\mathrm{kg}^{-1}\right)\end{array}$} & \multicolumn{3}{|c|}{$298.15 \mathrm{~K}$} & \multicolumn{3}{|c|}{$303.15 \mathrm{~K}$} & \multicolumn{3}{|c|}{$308.15 \mathrm{~K}$} & \multicolumn{3}{|c|}{$313.15 \mathrm{~K}$} \\
\hline & $\begin{array}{c}\pi_{\mathrm{i}} \times 10^{-10} \\
\left(\mathrm{Nm}^{-2}\right)\end{array}$ & $\begin{array}{c}\mathrm{L}_{\mathrm{f}} \times 10^{11} \\
(\mathrm{~m})\end{array}$ & $\begin{array}{c}\mathrm{V}_{\mathrm{f}} \times 10^{13} \\
\left(\mathrm{~m}^{3}\right. \\
\left.\mathrm{mol}^{-1}\right)\end{array}$ & $\begin{array}{l}\pi_{\mathrm{i}} \times 10^{-10} \\
\left(\mathrm{Nm}^{-2}\right)\end{array}$ & $\begin{array}{c}\mathrm{L}_{\mathrm{f}} \times 10^{11} \\
(\mathrm{~m})\end{array}$ & $\begin{array}{c}\mathrm{V}_{\mathrm{f}} \times 10^{13} \\
\left(\mathrm{~m}^{3}\right. \\
\left.\mathrm{mol}^{-1}\right)\end{array}$ & $\begin{array}{c}\pi_{\mathrm{i}} \times 10^{-10} \\
\left(\mathrm{Nm}^{-2}\right)\end{array}$ & $\begin{array}{c}\mathrm{L}_{\mathrm{f}} \times 10^{11} \\
(\mathrm{~m})\end{array}$ & $\begin{array}{c}\mathrm{V}_{\mathrm{f}} \times 10^{13} \\
\left(\mathrm{~m}^{3}\right. \\
\left.\mathrm{mol}^{-1}\right)\end{array}$ & $\begin{array}{c}\pi_{\mathrm{i}} \times 10^{-10} \\
\left(\mathrm{Nm}^{-2}\right)\end{array}$ & $\begin{array}{c}\mathrm{L}_{\mathrm{f}} \times 10^{11} \\
(\mathrm{~m})\end{array}$ & $\begin{array}{c}\mathrm{V}_{\mathrm{f}} \times 10^{13} \\
\left(\mathrm{~m}^{3}\right. \\
\left.\mathrm{mol}^{-1}\right)\end{array}$ \\
\hline \multicolumn{13}{|c|}{ Tetra- $n$-butylammonium bromide in $10 \%$ 1,3-dioxolane + water } \\
\hline 0.000 & 7.880 & 4.168 & 6.609 & 7.554 & 4.196 & 7.872 & 7.252 & 4.220 & 9.320 & 6.976 & 4.248 & 10.954 \\
\hline 0.001 & 7.855 & 4.165 & 6.634 & 7.530 & 4.193 & 7.902 & 7.228 & 4.217 & 9.357 & 6.954 & 4.246 & 10.993 \\
\hline 0.005 & 7.772 & 4.156 & 6.683 & 7.444 & 4.184 & 7.981 & 7.146 & 4.209 & 9.447 & 6.876 & 4.238 & 11.097 \\
\hline 0.008 & 7.709 & 4.154 & 6.746 & 7.388 & 4.182 & 8.040 & 7.094 & 4.207 & 9.513 & 6.825 & 4.236 & 11.175 \\
\hline 0.010 & 7.644 & 4.153 & 6.814 & 7.331 & 4.181 & 8.107 & 7.039 & 4.206 & 9.593 & 6.770 & 4.232 & 11.277 \\
\hline 0.021 & 7.386 & 4.144 & 7.114 & 7.085 & 4.173 & 8.455 & 6.803 & 4.199 & 10.002 & 6.542 & 4.223 & 11.768 \\
\hline 0.042 & 6.913 & 4.137 & 7.721 & 6.630 & 4.167 & 9.178 & 6.366 & 4.194 & 10.851 & 6.122 & 4.218 & 12.768 \\
\hline 0.064 & 6.493 & 4.130 & 8.327 & 6.223 & 4.160 & 9.917 & 5.977 & 4.185 & 11.718 & 5.746 & 4.207 & 13.792 \\
\hline 0.087 & 6.101 & 4.120 & 9.016 & 5.845 & 4.150 & 10.749 & 5.615 & 4.175 & 12.686 & 5.399 & 4.198 & 14.929 \\
\hline 0.110 & 5.760 & 4.112 & 9.669 & 5.518 & 4.142 & 11.530 & 5.298 & 4.169 & 13.631 & 5.093 & 4.193 & 16.042 \\
\hline 0.133 & 5.430 & 4.100 & 10.463 & 5.201 & 4.131 & 12.476 & 4.995 & 4.158 & 14.748 & 4.802 & 4.184 & 17.348 \\
\hline 0.000 & 8.009 & 4.377 & 6.087 & 7.648 & 4.404 & 7.321 & 7.308 & 4.427 & 8.757 & 7.004 & 4.448 & 10.398 \\
\hline 0.001 & 7.992 & 4.374 & 6.088 & 7.636 & 4.401 & 7.312 & 7.296 & 4.424 & 8.743 & 6.995 & 4.446 & 10.374 \\
\hline 0.005 & 7.892 & 4.363 & 6.165 & 7.540 & 4.393 & 7.407 & 7.206 & 4.416 & 8.851 & 6.908 & 4.439 & 10.504 \\
\hline 0.008 & 7.824 & 4.358 & 6.231 & 7.478 & 4.388 & 7.475 & 7.148 & 4.413 & 8.928 & 6.850 & 4.436 & 10.605 \\
\hline 0.011 & 7.757 & 4.355 & 6.294 & 7.411 & 4.385 & 7.561 & 7.086 & 4.412 & 9.025 & 6.792 & 4.434 & 10.710 \\
\hline 0.021 & 7.491 & 4.348 & 6.570 & 7.156 & 4.378 & 7.895 & 6.843 & 4.406 & 9.420 & 6.559 & 4.427 & 11.180 \\
\hline 0.044 & 7.001 & 4.343 & 7.140 & 6.687 & 4.372 & 8.580 & 6.393 & 4.397 & 10.244 & 6.127 & 4.419 & 12.158 \\
\hline 0.066 & 6.566 & 4.336 & 7.715 & 6.271 & 4.365 & 9.271 & 5.994 & 4.389 & 11.072 & 5.745 & 4.411 & 13.141 \\
\hline 0.090 & 6.180 & 4.327 & 8.289 & 5.901 & 4.355 & 9.969 & 5.641 & 4.379 & 11.902 & 5.406 & 4.400 & 14.124 \\
\hline 0.113 & 5.840 & 4.320 & 8.848 & 5.576 & 4.349 & 10.638 & 5.331 & 4.374 & 12.690 & 5.109 & 4.396 & 15.058 \\
\hline 0.137 & 5.522 & 4.314 & 9.467 & 5.271 & 4.340 & 11.391 & 5.039 & 4.365 & 13.593 & 4.829 & 4.386 & 16.129 \\
\hline
\end{tabular}



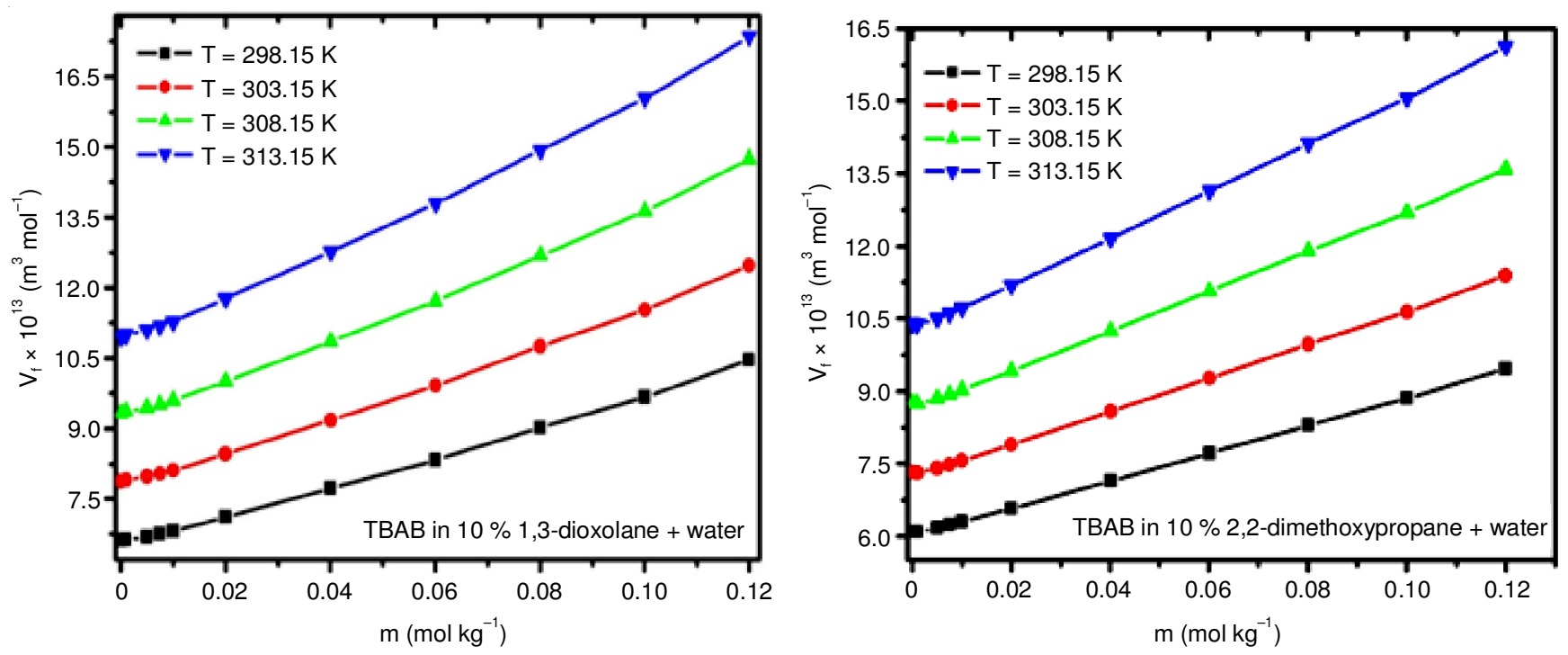

Fig. 2. Plot of free volume $\left(\mathrm{V}_{\mathrm{f}}\right) v s$. molality $(\mathrm{m})$ of solutions of tetra- $n$-butylammonium bromide (a) in $10 \% 1,3$-dioxolane + water and (b) in $10 \%$ 2,2-dimethoxypropane + water at 298.15-313.15 K

actions with increase in concentration and temperature. Further the decrease in compressibility $\left(\beta_{\mathrm{S}}\right.$ and $\left.\beta_{\mathrm{T}}\right)$ are expected due to the structure-making ability of tetra- $n$-butylammonium bromide. Bulkiness of tetra- $n$-butylammonium bromide decreases due to the insertion of co-solvents in the interstitial spaces of water, as the value of molar compressibility increases with increase in temperature.

\section{ACKNOWLEDGEMENTS}

One of the authors (BBN) from Vikram Deb Autonomous College thanks the Principal, Prof. (Mrs.) C. Sabitri and Head of the P.G. Department of Chemistry, Mr. Ranjan K. Pradhan for providing the infrastructure as an initiation for the improvement of research activities.

\section{REFERENCES}

1. A. Apelblat, J. Solution Chem., 36, 1437 (2007); https://doi.org/10.1007/s10953-007-9195-5.

2. F.J. Millero, in ed.: R.A. Horne, Water and Aqueous Solutions: Structure, Thermodynamics, and Transport Processes, Wiley-Interscience, New York, p. 519 (1972).

3. H.J. Ledon, Org. Synth., 59, 66 (1979); https://doi.org/10.15227/orgsyn.059.0066.

4. S.R. Aswale and S.S. Aswale, J. Chem. Res., 3, 233 (2011).

5. W.Y. Wen, ed.: R.A. Horne, Water and Aqueous Solutions, John Wile \& Sons: New York, Chap. 15, p. 613 (1972).

6. E.R. Nightingale Jr., J. Phys. Chem., 66, 894 (1962); https://doi.org/10.1021/j100811a032.

7. H.S. Frank and W.Y. Wen, Discuss. Faraday Soc., 24, 133 (1957); https://doi.org/10.1039/df9572400133.

8. H. Rueterjans, F. Schreiner, U. Sage and T. Ackermann, J. Phys. Chem., 73, 986 (1969);

https://doi.org/10.1021/j100724a038.

9. W.Y. Wen and S. Saito, J. Phys. Chem., 68, 2639 (1964); https://doi.org/10.1021/j100791a042.

10. R.A. Daignault and E.L. Eliel, Organic Synthesis Collections, vol. 5, p. 303 (1973).
11. G. Douheret and A. Pal, J. Chem. Eng. Data, 33, 40 (1988); https://doi.org/10.1021/je00051a014.

12. T.S. Murthy, B. Rambabu and K. Laxminarayana, Acoust. Lett., 17, 111 (1993)

13. E.R. Nightingale Jr., Phys. Chem., 66, 894 (1962); https://doi.org/10.1021/j100811a032.

14. P.S. Nikam and A.B. Nikumbh, J. Chem. Eng. Data, 47, 400 (2002); https://doi.org/10.1021/je0102762.

15. P.S. Nikam, H. Mehdi, T.B. Pawar and A.B. Sawant, Indian J. Pure Appl. Phys., 42, 172 (2004).

16. Y. Nagano, M. Sakiyama, T. Fujiwara and Y. Kondo, J. Phys. Chem., 92, 5823 (1988); https://doi.org/10.1021/j100331a054.

17. H. Hooshyar and B. Khezri, Phys. Chem. Liq., 54, 663 (2016); https://doi.org/10.1080/00319104.2016.1140762.

18. T.G. Coker, J. Ambrose and G.J. Janz, J. Am. Chem. Soc., 92, 5293 (1970); https://doi.org/10.1021/ja00721a001.

19. J.A. Kitchner, Findlay Practical Physical Chemistry, Longman: London, edn 8, p. 70 (1954).

20. M.N. Roy and B. Sinha, J. Mol. Liq., 133, 89 (2007); https://doi.org/10.1016/j.molliq.2006.07.009.

21. B. Sinha, B.K. Sarkar and M.N. Roy, J. Chem. Thermodyn., 40, 394 (2008); https://doi.org/10.1016/i.jct.2007.09.012.

22. B.B. Nanda, B. Nanda and P.C. Mohanty, J. Mol. Liq., 171, 50 (2012); https://doi.org/10.1016/j.molliq.2012.03.011.

23. B. Jacobson, P.A. Heedman, R. Pesola, A.I. Virtanen and N.A. Sörensen, Acta Chem. Scand., 7, 705 (1953); https://doi.org/10.3891/acta.chem.scand.07-0705.

24. D.O. Masson, Philos. Mag., 8, 218 (1929); https://doi.org/10.1080/14786440808564880.

25. B.B. Nanda, Indian J. Pure Appl. Phys., 54, 471 (2016).

26. G. Nath and R. Paikaray, Indian J. Phys., 83, 1309 (2009); https://doi.org/10.1007/s12648-009-0111-2.

27. B.B. Nanda, Int. J. Res. Rev. Pharm. Appl. Sci., 6, 1290 (2016).

28. J.F. Kincaid and H. Eyring, J. Chem. Phys., 6, 620 (1938); https://doi.org/10.1063/1.1750134.

29. S. Thirumaran and K.J. Sabu, Indian J. Pure Appl. Phys., 47, 87 (2009).

30. T.M. Aminabhavi, M.I. Aralaguppi, S.S. Joshi, S.B. Harogopped, R.S. Khinnavar and R.H. Balungi, Indian J. Technol., 30, 303 (1992).

31. C.V. Suryanarayana, J. Acoust. Soc. Ind., 7, 131 (1979). 